\title{
Hypotension and bradycardia, a serious adverse effect of piribedil, a case report and literature review
}

\author{
Piao Zhang ${ }^{1,2}$, Yan $\mathrm{Li}^{1}$, Kun Nie', Lijuan Wang ${ }^{1}$ and Yuhu Zhang ${ }^{1 *}$ (D)
}

\begin{abstract}
Background: Dopamine agonists (DAs) are efficacious for the treatment of motor and nonmotor symptoms in patients with Parkinson's disease (PD). The treatment of PD with DAs is often complicated by adverse drug reactions (ADRs) of dopaminergic and non-dopaminergic origins. The DA piribedil is widely used in Asian, European, and Latin American countries; therefore, its ADRs are pertinent to clinicians. Here we present a rare case of hypotension and bradycardia that is significantly related to the dosage of piribedil.

Case presentation: A middle-aged male, diagnosed with PD, received dopamine replacement with piribedil. When taking $50 \mathrm{mg}$ piribedil daily dose, the patient didn't feel any discomfort. Two hours after taking $100 \mathrm{mg}$ piribedil he presented with serious concomitant hypotension and bradycardia with a blood pressure (BP) reading of 85/48 $\mathrm{mmHg}$ and a heart rate (HR) of 45 beats/min when sitting. After taking $75 \mathrm{mg}$ piribedil, the patient showed the same symptoms with BP reading at $70 / 45 \mathrm{mmHg}$ and $\mathrm{HR}$ of 47 beats/min in the same position. Upon replacing treatment with pramipexole $0.125 \mathrm{mg}, 0.25 \mathrm{mg}$, and $0.375 \mathrm{mg}$ three times a day, no further cardiovascular effects persisted.

Conclusions: No studies have previously reported the simultaneous observation of position-unrelated hypotension and bradycardia after taking small doses of piribedil. More studies are needed to explore the effects of DAs on BP and $H R$, especially piribedil. Piribedil is efficacious for the treatment of PD, but it is important to weigh the potential risk of hypotension and bradycardia against the clinical benefits of this drug.
\end{abstract}

Keywords: Piribedil, Hypotension, Bradycardia, Parkinson's disease, Adverse drug reactions

\section{Background}

Parkinson's disease (PD) is a neurodegenerative disease of dopamine neurons in the substantia nigra. According to a recent report, the incidence rate of PD for all age groups is between 1.5 and 22 per 100,000 person-years, placing an increasing burden on our families and society [1]. DAs used in PD treatment are a feasible supplement to levodopa, and the combined treatment has shown fewer motor complications than when levodopa is used in isolation [2]. Orthostatic hypotension is a well-known adverse effect associated with the administration of DAs at any point, and arises as an acute effect when starting the medication [3]. However, current literature on

\footnotetext{
* Correspondence: yhzhangsd@126.com

${ }^{1}$ Department of Neurology, Guangdong Neuroscience Institute, Guangdong General Hospital, Guangdong Academy of Medical Sciences, Guangzhou 510080, Guangdong province, China

Full list of author information is available at the end of the article
}

concomitant hypotensive and bradycardic effects of piribedil after oral administration has not been found.

\section{Case}

A 62 year-old male had displayed bradykinesia and tremor of his right limbs for one year, during which he was able to perform limited fine movements such as dressing himself, lacing up his shoes and brushing his teeth. His tremors were aggravated by nervousness and relieved when asleep. He had had a history of hypertension and took a daily dose of $5 \mathrm{mg}$ amlodipine. The patient had no history of any other chronic illnesses and was not on any other type of medication. Neither the electrocardiogram nor the Holter monitor showed any abnormalities. His baseline recumbent-upright blood pressure (BP) and heart rate (HR) were normal prior to treatment with piribedil, as shown in Table 1 . He was diagnosed with PD based on the Movement Disorder

(c) The Author(s). 2018 Open Access This article is distributed under the terms of the Creative Commons Attribution 4.0 International License (http://creativecommons.org/licenses/by/4.0/), which permits unrestricted use, distribution, and 
Table 1 BP and HR in lying and standing position before taking and after stopping taking piribedil

\begin{tabular}{lllllll}
\hline & & Lying & Standing for 1 min & Standing for 3 min & Standing for 5 min & Standing for 7 min \\
\hline Before & BP $(\mathrm{mmHg})$ & $123 / 67$ & $118 / 72$ & $116 / 70$ & $117 / 71$ & $124 / 73$ \\
& HR (beats/min) & 74 & 86 & 85 & 82 & 84 \\
After & BP (mmHg) & $125 / 72$ & $122 / 79$ & $125 / 83$ & $129 / 79$ & $126 / 82$ \\
& HR (beats/min) & 70 & 89 & 88 & 86 & 88 \\
\hline
\end{tabular}

Society clinical diagnostic criteria [4]. Initially, he received dopamine replacement therapy of $50 \mathrm{mg}$ piribedil per day. Although there was no significant improvement in symptoms neither did he feel any discomfort. Therefore, starting the first dose change of piribedil, he added extra $50 \mathrm{mg}$ to his dose. About two hours later after the first change in dose, the patient experienced symptoms of dizziness and sweating; he collapsed half an hour later. Whilst in a sitting position, the patient's BP and $\mathrm{HR}$ were measured immediately. The BP reading was $85 / 48 \mathrm{mmHg}$ and HR was 45 beats/min. His symptoms continued for the duration of the day with sitting BP fluctuating between $80-95 \mathrm{mmHg}$ to $45-68 \mathrm{mmHg}$. Because his head computerized tomography examination found no abnormalities, the patient received $500 \mathrm{~mL}$ of $0.9 \%$ sodium chloride solution, after which his symptoms improved. Due to adverse drug reactions (ADRs), the patient was started on a second dose change of piribedil, i.e. an extra dose of $25 \mathrm{mg}$ piribedil was to be taken in the afternoon in addition to the existing $50 \mathrm{mg}$ taken in the morning. After two and a half hours, the patient experienced dizziness, sweating, nausea and vomiting, with a BP reading of $70 / 45 \mathrm{mmHg}$ and a HR of 47 beats/ min when sitting. His BP recovered to $105 / 65 \mathrm{mmHg}$ and HR to 60 beats/min after elevating his lower limbs and resting for 20 mins. As a result of these incidences, the patient was switched to pramipexole to replace piribedil. After taking pramipexole $0.125 \mathrm{mg}$ or $0.25 \mathrm{mg}$ three times a day (tid), the symptoms of hypotension and bradycardia disappeared but a reduced amplitude of his right arm swing was still observed. Finally, after the pramipexole dose was increased to $0.375 \mathrm{mg}$ tid, the patient showed marked improvements in motor symptoms. The changes in BP and HR are shown in Fig. 1.

\section{Discussion}

This case demonstrated the close relationships between $\mathrm{BP}$ and HR with the piribedil dosage and between BP and $H R$ with the time frame of symptom appearance, i.e. the patient exhibited symptomatic hypotension and bradycardia after approximately $2 \mathrm{~h}$ after administration of piribedil treatment, which is roughly the time piribedil

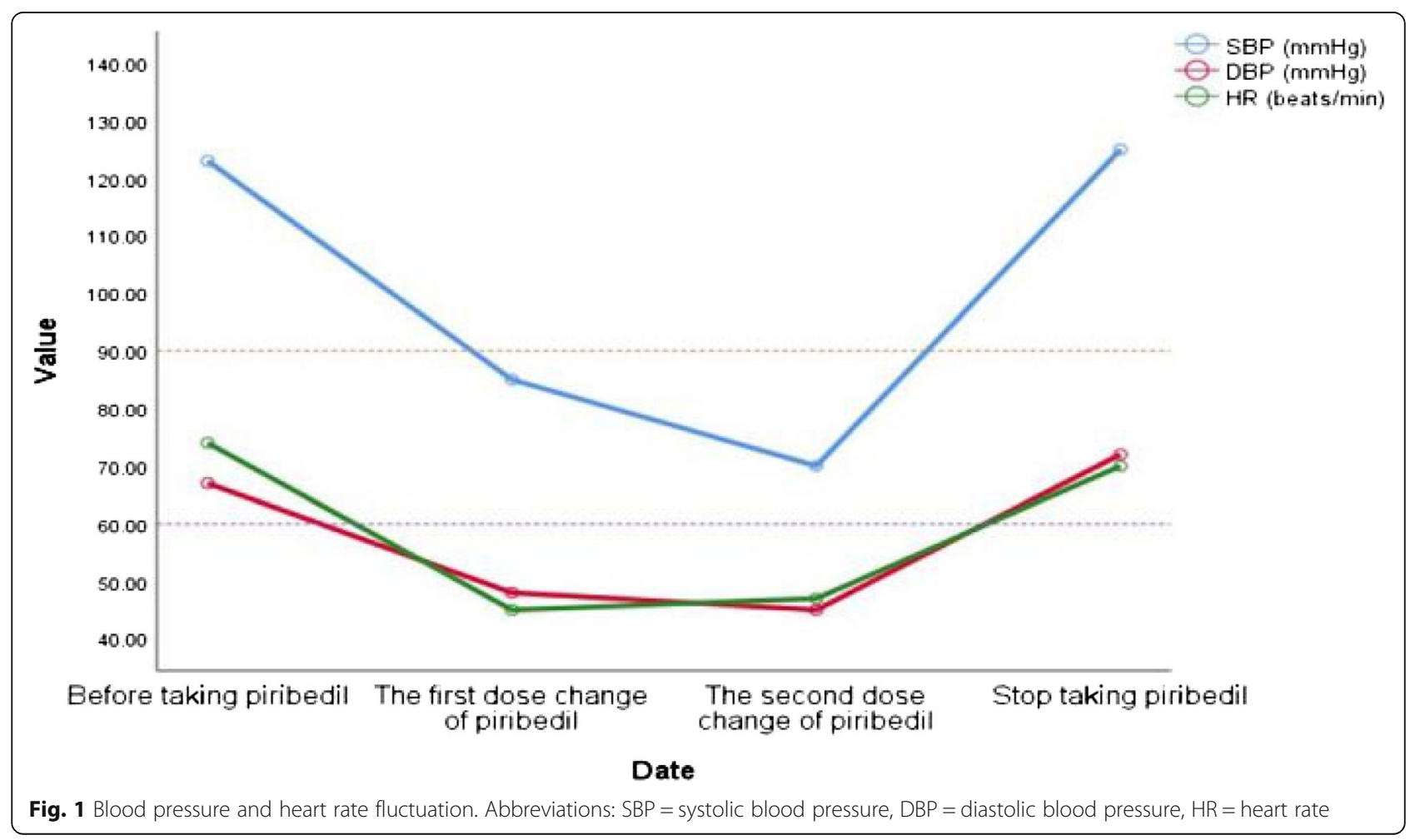


would take to reach maximum concentration, i.e. $1 \mathrm{~h} \mathrm{[5].}$ Because of this close relationship hypotension and bradycardia were the resulting adverse effects of piribedil. After the oral administration of piribedil, the patient was initially diagnosed with anaphylactic shock [6] after observing a systolic BP decrease of greater than 30\% from baseline. However, since the patient did not display any allergic reactions, he was finally diagnosed with concomitant hypotension and bradycardia; these symptoms were unlike other cases and had not been reported before.

DAs for the treatment of PD are divided into two categories; one is ergot (i.e., bromocriptine, cabergoline, lisuride and pergolide), the other is non-ergot (i.e., apomorphine, piribedil, pramipexole, ropinirole and rotigotine). All DAs possess high affinity for the D2-like family of dopamine receptors (which include the D2, D3, D4 receptors), but the ergot DAs have a higher affinity for alpha-adrenergic (alpha-1 and alpha-2) and serotonergic (5-HT1 and 5-HT2) receptors than non-ergot DAs. A review summarized a series of ADRs associated with DAs, including peripheral and central reactions [7]. The former comprises gastrointestinal reactions such as nausea and vomiting, cardiovascular reactions such as orthostatic hypotension and leg edema, while the latter includes psychotic or behavioral syndromes and sedative reactions [7]. A previous meta-analysis concluded that the recurrence of somnolence, hallucination and anxiety was much higher with non-ergot DAs, whereas the frequencies of depression, vomiting, or arterial hypotension were higher with ergot DAs [8], although it remains unclear whether this discrepancy was caused by the different receptors between ergot and non-ergot DAs. Nonetheless, it has been proven that some ADRs are associated with different receptor properties, for example, 5-HT2 receptors are potentially related to the pathogenesis of valvular heart disorders [9]; Meanwhile, stimulation of alpha-2 adrenergic receptors increases the occurrence of dyskinesias, while alpha-2 adrenergic antagonists have been shown to reduce levodopa-induced dyskinesias [10]. This is consistent with the higher incidence of dyskinesias reported for the alpha-2 adrenergic receptor agonist, pergolide [10], whilst alpha-1 adrenoreceptors are mainly associated with cardiovascular function [11]. Apomorphine hydrochloride and bromocriptine mesylate reduce BP in normal and hypertensive individuals, so they may been used in patients with hypertension [12]. There are conflicting evidences about the mechanism of hypotension in ergot DAs. In addition to decreasing the adrenal catecholamine levels, plasma aldosterone levels and renin activity associated with antihypertensive effect, the use of DAs have also evidenced improvement in renal functions, increase of inulin clearance and a decline in renal vascular resistance $[12,13]$. Furthermore, ergot DAs have been proven to stimulate peripheral dopamine receptors and inhibit sympathetic nerves [13, 14]. Most of the research on DA-induced hypotension showed an accompanying increase in HR. One study suggested that the acute orthostatic hypotension might be a direct effect of dopamine receptors instead of the clinical illness or concurrent medications, which could have also resulted in lowered BP [3].

Piribedil, a representative of non-ergot DAs, is a D2/ D3 dopamine receptor agonist to improve motor symptoms in early PD patients and motor fluctuations in advanced $P D$ patients by simultaneously blocking alpha- 2 adrenoreceptors and exerting minimal effects on serotoninergic, cholinergic, and histaminergic receptors, and can also improve non-motor symptoms such as vigilance, attention, memory and mood [15]. piribedil is hepatically metabolized (mainly demethylation, p-hydroxylation, and $\mathrm{N}$-oxidation) and produces many metabolites, one of which is a D1 agonist [16]; Orthostatic hypotension has always been characterized as a common cardiovascular adverse effect that emerges within the first week of piribedil use, accounting for $5 \%$ of ADRs for this drug [17].

An interesting finding showed that the intravenous administration of quinpirole-dose-dependent, selective DAs could significantly lead to hypotension and bradycardia in anaesthetised normotensive rats via dopamine D2 receptors located in peripheral circulation and within the spinal cord. This finding is consistent with results seen in later studies. $[18,19]$. The similar symptoms observed in this case may be a mechanism of the dopamine D2 receptors in the spinal cord. Another research, however, pointed out that intravenous administration of apomorphine produced hypotension and bradycardia through presynaptic dopamine autoreceptors [20]. In healthy subjects, the dopamine D2/D3 receptors binding in striatum relates negatively to supine resting systolic BP and HR [21]. Previous investigations have shown that D2 receptors are mainly located presynaptically on 1) sympathetic nerves where they inhibit norepinephrine release, and in 2) autonomic ganglia where they reduce ganglionic transmission once activated. The use of piribedil can directly cause hypotensive effects and a fall in HR by acting primarily on the peripheral presynaptic D2 receptor to reduce the release of the norepinephrine. Since domperidone, a D2-receptor antagonist which does not cross the blood-brain barrier, can completely block the hypotensive effects and partially block the bradycardia effects of piribedil, this may indirectly confirm that the bradycardic effect of piribedil is via central action to some extent $[21,22]$. Stimulation of the dopamine receptors in the central system can result in a decrease in the sympathetic outflow.

It has been established that alpha- 2 adrenoceptors are located presynaptically on the locus coeruleus neurons, which contributes centrally to autonomic functions via the release of noradrenaline [23]. Exposure to alpha-2 adrenoceptor agonists (e.g. clonidine) would mediate 
inhibitory effects on noradrenergic pathways, leading to increased activity of parasympathetic nervous system and reduced activity of sympathetic nervous system, thus lowering blood pressure; alpha-2 adrenoceptor antagonists, such as yohimbine, would derive the opposite effect [23]. Piribedil, with the properties of an alpha-2 adrenoreceptor antagonist, can cause autonomic-cardiovascular effects via the blockade of central and peripheral alpha-2 adrenoreceptors that inhibit the sympathetic nervous system [24]. Theoretically, piribedil may increase BP. However, in another alpha-2 receptor antagonist, atipamezole, the cardiovascular side-effects was not observed with low dose, however an increase in BP was observed with relatively higher dose [25];it remains to see with further investigation whether the same cardiovascular effect will be observed when on low doses of piribedil.

D1 receptors, primally located in vascular smooth muscle of renal and visceral beds, produce hypotensive effects via vasodilation and are accompanied by an increase in HR due to a baroreceptor reflex [26]. Piribedil may also have a role as a D1 receptor agonist due to its metabolites, however this remains to be proven [16]. In addition to its action on peripheral presynaptic D2 receptors and central system, piribedil plays a role in hypotension by stimulating the peripheral D1 receptors, which is followed by the increase in HR owing to a reflexive increase of sympathetic activity to the vasodilatory effect on the peripheral artery [13]. But the patient in our case showed an obvious decrease in HR. In summary, piribedil exerts its effect on hypotension and bradycardia possibly via D2 receptors.

Pramipexole, a non-ergot dopamine agonist with novel properties, has the highest affinity of the dopamine D2 receptor subfamily and shows preferential affinity for the D3 receptor subgroup. Apart from dopamine receptors, pramipexole also binds to alpha-2 adrenoceptors [27]. The pharmacokinetic index of pramipexole is linear and the plasma concentration increases with dosage. Pramipexole is well absorbed after administration but is hardly metabolized and is excreted unchanged in the urine. The peak plasma concentration of pramipexole occurs after oral administration for $1-3 \mathrm{~h}$, with its half-life ranging from 8 to $12 \mathrm{~h}$ [28]. Currently, cardiovascular ADRs of pramipexole possibly include leg edema, but not orthostatic hypotension and heart failure. Orthostatic hypotension has not been associated with pramipexole, possibly because pramipexole shows higher affinity for the D3 receptors and the D1, D3, D4 dopamine receptors show no major effects on the heart; meanwhile, the D2 agonists would decrease heart rate as well as left ventricular contractility [19]. According to a meta-analysis, the use of non-ergot DAs including pramipexole in PD patients was not associated with an increased risk of incident heart failure, nor did it show an increase in the overall mortality or the risk of cardiovascular events compared with the PD patients taking monotherapy with levodopa alone [29].

In summary, piribedil can produce D1 agonist metabolites, whereas pramipexole is hardly metabolized and is delivered unchanged from urine, which may explain the lack of hypotension with pramipexole use, but not bradycardia. The lower risk of hypotension and bradycardia with pramipexole could also be understood through the perspective of receptor interactions, whereby pramipexole has higher affinity for D3 receptor.

Currently, the simultaneous appearance of hypotension and bradycardia after taking DAs is rarely observed, whether in clinical practice or research, because hypotension followed by an increase in HR has been the general observation. In addition, current studies mainly investigate orthostatic hypotension rather than positionunrelated hypotension. Based on the existing literature, the current observations of the ADRs associated with piribedil use are not a surprise. Until now it remains unknown whether the sympathetic nerve activity and renin-angiotensin-aldosterone system play an important role in hypotension and bradycardia together with piribedil. The patient in our case experienced hypotension and bradycardia associated directly with piribedil intake irrespective of standing or lying positions. This was at odds with previous reports, suggesting that piribedil may probably lead to concomitant hypotension and bradycardia via inhibition of sympathetic nerve activity and decreasing of plasma renin activity and plasma aldosterone, along with activating peripheral and central D1 dopaminergic receptor, which needs further studies to confirm. If future cases of piribedil use present similar observations, piribedil should be stopped and the situation should be remedied with fluid replacement. More research is urgently needed to explore the incidence and mechanisms of concomitant hypotension and bradycardia caused by DAs.

\section{Abbreviations}

ADRs: Adverse drug reactions; BP: Blood pressure; DAs: Dopamine agonists; DBP: Diastolic blood pressure; HR: Heart rate; PD: Parkinson's disease; SBP: Systolic blood pressure

\section{Acknowledgements}

We would like to express our gratitude to the staff of both hospitals for the support and help with valuable information during the writing process.

\section{Funding}

This work was supported by grants of Key Program of Natural Science Foundation of Guangdong Province, China (NO. 2017B030311015), Natural Science Foundation of Guangdong Province, China (NO. 2015A030313536), Medical Research Fund of Guangdong Province, China (NO. A2017317), National Key R\&D Program of China (NO. 2017YFC1310200), National Natural Science Foundation of China (NO. 81671275, NO. 81501112). The grants of Key Program of Natural Science Foundation of Guangdong Province provide financial aid to the data collection of the manuscript; grants of natural Science Foundation of

Guangdong Province contribute to the analyzed data of the manuscript; grants of Medical Research Fund of Guangdong Province and National Key R\&D Program of China offer interpretation of data; two grants of National Natural Science Foundation of China pay fee for polishing English language of the manuscript and publication charges. 


\section{Availability of data and materials}

All data generated or analysed during this study are included in this published article.

\section{Authors' contributions}

PZ acquired the clinical data and drafted the manuscript. YL, KN, LW make a lot contributions to obtain data of heart rate and blood pressure, simultaneously help explain the relationship between piribedil and bradycardia and hypotension. Moreover, they participate in modifying the comparison between piribedil and pramipexole. YZ revised the manuscript and contributed the conception of the manuscript. All authors have read and approved the final version of the manuscript.

\section{Ethics approval and consent to participate}

Not applicable.

\section{Consent for publication}

Written informed consent was obtained from the patient for publication of this case report.

\section{Competing interests}

The authors declare that they have no conflict of interest.

\section{Publisher's Note}

Springer Nature remains neutral with regard to jurisdictional claims in published maps and institutional affiliations.

\section{Author details}

'Department of Neurology, Guangdong Neuroscience Institute, Guangdong General Hospital, Guangdong Academy of Medical Sciences, Guangzhou 510080, Guangdong province, China. ${ }^{2}$ The Second School of Clinical Medicine, Southern Medical University, Guangzhou 510515, Guangdong province, China.

\section{Received: 12 April 2018 Accepted: 19 December 2018}

Published online: 27 December 2018

\section{References}

1. Wirdefeldt K, Adami HO, Cole P, Trichopoulos D, Mandel J. Epidemiology and etiology of Parkinson's disease: a review of the evidence. Eur J Epidemiol. 2011;26(Suppl 1):S1-58.

2. Wood LD. Clinical review and treatment of select adverse effects of dopamine receptor agonists in Parkinson's disease. Drugs Aging. 2010;27(4): 295-310.

3. Kujawa K, Leurgans S, Raman R, Blasucci L, Goetz CG. Acute orthostatic hypotension when starting dopamine agonists in Parkinson's disease. Arch Neurol. 2000:57(10):1461-3.

4. Postuma RB, Berg D, Stern M, Poewe W, Olanow CW, Oertel W, Obeso J, Marek K, Litvan I, Lang AE, et al. MDS clinical diagnostic criteria for Parkinson's disease. Mov Disord. 2015;30(12):1591-601.

5. Nyholm D. Pharmacokinetic optimisation in the treatment of Parkinson's disease : an update. Clin Pharmacokinet. 2006:45(2):109-36.

6. Limsuwan T, Demoly P. Acute symptoms of drug hypersensitivity (urticaria, angioedema, anaphylaxis, anaphylactic shock). Med Clin North Am. 2010; 94(4):691-710 x.

7. Perez-Lloret S, Rascol O. Dopamine receptor agonists for the treatment of early or advanced Parkinson's disease. CNS Drugs. 2010;24(11):941-68.

8. Stowe RL, Ives NJ, Clarke C, van Hilten J., Ferreira J, Hawker RJ, Shah L, Wheatley K, Gray R: Dopamine agonist therapy in early Parkinson's disease. Cochrane Database Syst Rev 2008(2):Cd006564.

9. Antonini A, Poewe W. Fibrotic heart-valve reactions to dopamine-agonist treatment in Parkinson's disease. Lancet Neurol. 2007:6(9):826-9.

10. Kvernmo T, Houben J, Sylte I. Receptor-binding and pharmacokinetic properties of dopaminergic agonists. Curr Top Med Chem. 2008;8(12):1049-67.

11. Guimaraes S, Moura D. Vascular adrenoceptors: an update. Pharmacol Rev. 2001;53(2):319-56.

12. Montastruc JL, Chamontin B, Rostin M, Rascol O, Valet P, Gaillard G, Tran MA, Van TT, Ader JL, Montastruc P. Experimental and clinical approaches to treatment of hypertension by dopamine receptor agonists. Clin Exp Hypertens A. 1987;9(5-6):1069-84.
13. Luchsinger A, Velasco M, Urbina A, Morillo J, Romero E, Alvarez R, Pieretti $\mathrm{OH}$. Comparative effects of dopaminergic agonists on cardiovascular, renal, and renin-angiotensin systems in hypertensive patients. J Clin Pharmacol. 1992:32(1):55-60.

14. Montastruc JL, Rascol O, Senard JM. Current status of dopamine agonists in Parkinson's disease management. Drugs. 1993:46(3):384-93.

15. Perez-Lloret S, Rascol O. Piribedil for the treatment of motor and non-motor symptoms of Parkinson disease. CNS drugs. 2016;30(8):703-17.

16. Jenner P. Parkinson's disease: pathological mechanisms and actions of piribedil. J Neurol. 1992;239(Suppl 1):S2-8

17. Hollingworth SA, McGuire TM, Pache D, Eadie MJ. Dopamine agonists: time pattern of adverse effects reporting in Australia. Drugs -Rreal World Outcomes. 2015;2(3):199-203.

18. Lahlou S. Involvement of spinal dopamine receptors in mediation of the hypotensive and bradycardic effects of systemic quinpirole in anaesthetised rats. Eur J Pharmacol. 1998;353(2-3):227-37.

19. Polakowski JS, Segreti JA, Cox BF, Hsieh GC, Kolasa T, Moreland RB, Brioni JD. Effects of selective dopamine receptor subtype agonists on cardiac contractility and regional haemodynamics in rats. Clin Exp Pharmacol Physiol. 2004;31(12):837-41.

20. Chueh FY, Hsieh MT, Chen CF, Lin MT. DL-tetrahydropalmatine-produced hypotension and bradycardia in rats through the inhibition of central nervous dopaminergic mechanisms. Pharmacology. 1995;51(4):237-44.

21. McCoy CE, Douglas FL, Goldberg LI. Selective antagonism of the hypotensive effects of dopamine agonists in spontaneously hypertensive rats. Hypertension. 1986;8(4):298-302

22. Cavero I, Massingham R, Lefevere-Borg F. Peripheral dopamine receptors, potential targets for a new class of antihypertensive agents. Part II: sites and mechanisms of action of dopamine receptor agonists. Life Sci. 1982;31(11): 1059-69.

23. Samuels ER, Szabadi E. Functional neuroanatomy of the noradrenergic locus coeruleus: its roles in the regulation of arousal and autonomic function part II: physiological and pharmacological manipulations and pathological alterations of locus coeruleus activity in humans. Curr Neuropharmacol. 2008:6(3):254-85.

24. Millan MJ. From the cell to the clinic: a comparative review of the partial $D(2) / D(3)$ receptor agonist and alpha2-adrenoceptor antagonist, piribedil, in the treatment of Parkinson's disease. Pharmacol Ther. 2010;128(2):229-73.

25. Pertovaara A, Haapalinna A, Sirvio J, Virtanen R. Pharmacological properties, central nervous system effects, and potential therapeutic applications of atipamezole, a selective alpha2-adrenoceptor antagonist. CNS Drug Rev. 2005;11(3):273-88

26. Murphy MB, Elliott WJ. Dopamine and dopamine receptor agonists in cardiovascular therapy. Crit Care Med. 1990;18(1 Pt 2):S14-8.

27. Pinter MM, Pogarell O, Oertel WH. Efficacy, safety, and tolerance of the nonergoline dopamine agonist pramipexole in the treatment of advanced Parkinson's disease: a double blind, placebo controlled, randomised multicentre study. J Neurol Neurosurg Psychiatry. 1999;66(4):436-41.

28. Wright CE, Sisson TL, Ichhpurani AK, Peters GR. Steady-state pharmacokinetic properties of pramipexole in healthy volunteers. J Clin Pharmacol. 1997;37(6):520-5

29. De Vecchis R, Cantatrione C, Mazzei D, Baldi C, Di Maio M. Non-ergot dopamine agonists do not increase the risk of heart failure in Parkinson's disease patients: a meta-analysis of randomized controlled trials. J Clin Med Res. 2016;8(6):449-60.

Ready to submit your research? Choose BMC and benefit from:

- fast, convenient online submission

- thorough peer review by experienced researchers in your field

- rapid publication on acceptance

- support for research data, including large and complex data types

- gold Open Access which fosters wider collaboration and increased citations

- maximum visibility for your research: over $100 \mathrm{M}$ website views per year

At $\mathrm{BMC}$, research is always in progress.

Learn more biomedcentral.com/submissions 